\title{
Research on Engine Speed Control System Based on Fuzzy Adaptive PID Controller
}

\author{
Hairui Wang ${ }^{1}$, Lu Wang ${ }^{1}$, Yongyi Liao ${ }^{2, *}$, Hongwei Yang ${ }^{3}$ \\ ${ }^{1}$ Faculty of Information Engineering and Automation, Kunming University of Science and Technology, China. \\ ${ }^{2}$ Continuing Education College, Kunming University of Science and Technology, Kunming 650051, China. \\ ${ }^{*}$ Corresponding author E-mail: yongyiliao@163.com \\ ${ }^{3}$ Education Department of Yunnan Province, China.
}

\begin{abstract}
Traditional PID fails to meet the requirements in control precision and response speed while implementing a nonlinear control. Such problem can be easily solved by adaptive fuzzy PID, which indicates that the adaptive fuzzy PID will realize the precise control in engine speed control system, a typical nonlinear system. This paper first discusses the mathematical control model of diesel engine speed-control system and the characteristics of the traditional PID control. Then, the speed control principle of the adaptive fuzzy PID controller is analyzed. Besides, the membership function of fuzzy logical, the fuzzy logical variable and the fuzzy reasoning rules are determined. Next, the adaptive correction method is briefly introduced. Finally, the model of traditional PID and adaptive fuzzy PID controller are simulated and the same disturb is added into the control systems. The simulation results show that the adaptive fuzzy PID controller has better performance in dynamic response and robustness than that of traditional PID.
\end{abstract}

Keywords: Diesel Engine, Adaptive fuzzy PID controller, Speed-control system

\section{Introduction}

When a diesel engine is running, its online operating parameters and real time state are vulnerable to external interference. Thus, it is difficult to establish the accurate mathematical control model [1] to form the formula. Even the mathematical control model and the formula is established, it is still hard to veritably describe the more complicated system characteristics [2]. When it comes to real time system, for example, an real time electronic speedcontrol system, it becomes a great challenge to reduce the influence, often unexpected, of nonlinearities, time variant, outer disturb and so on to achieve a more precise control effect while handling the diesel engine control in the real time electronic speed-control system, which is what the research paper is required to solve.

Based on the present research, there are two main methods to solve the nonlinear control problem of the real time electronic speed control-system, one is to focus on the precise establishment of the mathematical control model which is mainly based on optimization of control theory and control algorithm, the other is to depend on the development of the actuator and key components [3]. The main goal of the research of control theory and control algorithm is not only to find ways to improve the traditional PID's control effect, but also to carry out new methods to avoid the unstable factors in the system caused by PID control effect [4]. The diesel engine control problem in the real time electronic speed-control system is hard to be settled by the traditional PID controller, because the nonlinear and time degeneration troubles, usually caused by frequent changes in speed, load and other factors of the diesel engine, are far beyond the capacity of the traditional PID controller to accommodate. So, only using traditional PID controller to compensate the instability of the system caused by parameters changes will be somewhat rocky.

The main purpose of this research is that no matter how external factors change, we may still achieve real time electronic control to speed-control system of diesel engine by means of adaptive fuzzy PID control algorithm even under the condition of nonlinear interference or more unexpected disturbance, thereby enhancing the precise control effect of diesel engine level, to ensure that the diesel engine operates reliably and stably. Although the accurate model of diesel engine control system is hard to build, the model simulation has been widely used to implement experimentation [5-7]. The nonlinear inference of the system can be achieved by adding disturb into the model.

\section{The mathematical control model of diesel en- gine speed-control system}

Diesel engine will be influenced by continuously changing load when it is running, and the diesel engine speed will produce fluctuations due to continuously changing of the load. Therefore, stabilizing diesel engine speed in the case of continuously changing load is the core task of real time automated speed-control system. According to the acceleration pedal angle sensor signal and rotate speed signal, the target valueof gear lever position can be calculated. Comparingwith measured valueof gear lever position, the deviation value of gear lever position can be calculated too. Measuring the actual engine speed with set speed, the speed deviation quantity can be acquired. All those parameters are essential for building the control model.

In order to analyze the transient process of the diesel engine control system, it is necessary to establish an appropriate mathematical control model for the diesel engine system. Only after that, the diesel system can be analyzed and researched correctly based on the mathematical control model. The research need build an appropriate mathematical control model to describe the movement of the diesel engine system, which is the most critical and 
difficult step for the study of the real time automatic diesel control system [8]. When the mathematical control model is established, the mathematical control model of every component in the system can be established consequently. And finally, the mathematical control model of the whole speed control system can be established based on the mathematical control model of every component. The operational diagram of automated diesel engine speed control system is shown in Fig. 1.

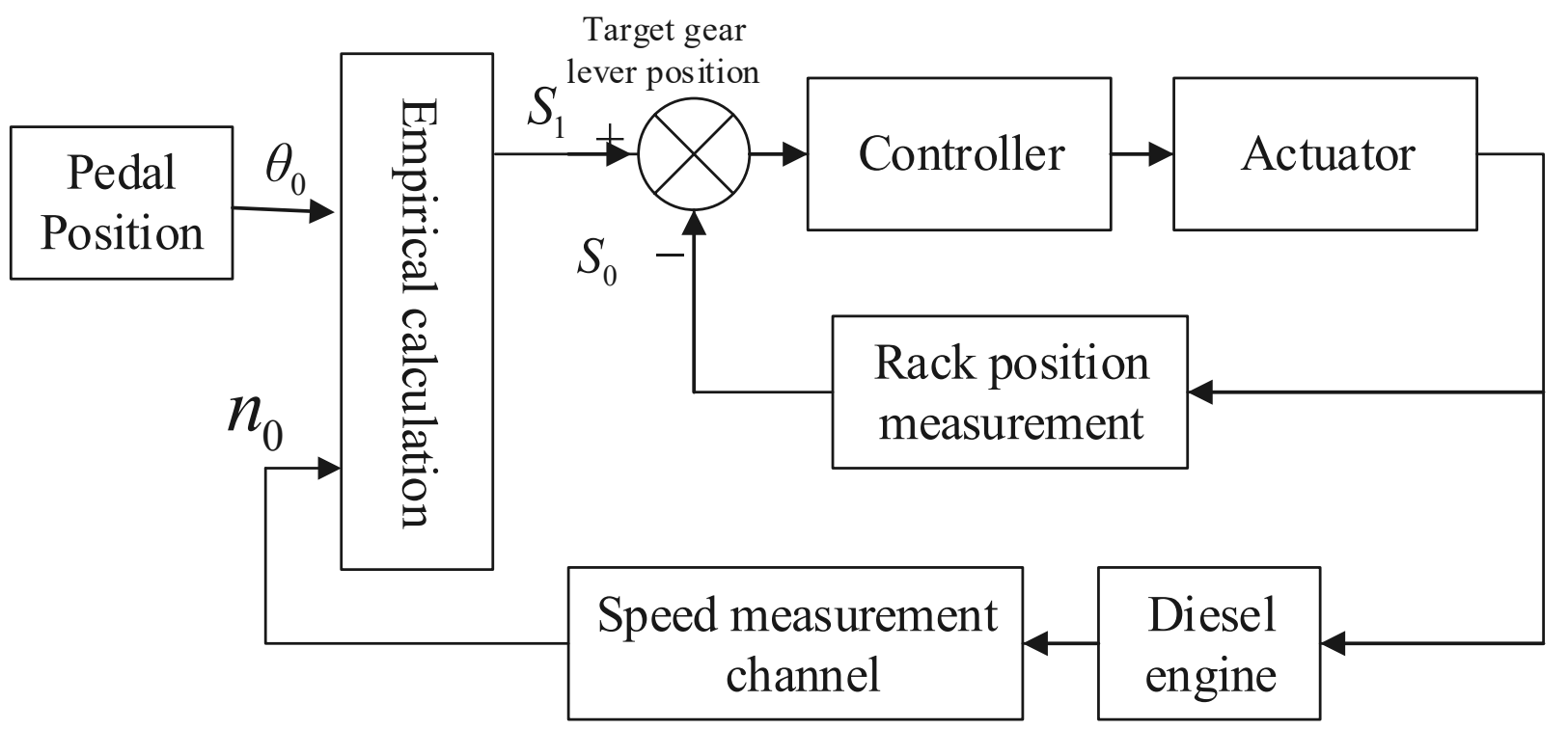

Fig. 1 Operational diagram of real time automated diesel speed-control system

\subsection{The engine}

Because of the massive number of state variables of the engine and the numerous characteristics of nonlinear and others, simple first-order model simulation can be used to build an approximate model. The dynamic process of an engine is expressed nearly by a pure hysteresis first-order inertia link, and its mathematical function is as follows (1):

$$
G_{1}(t)=A \frac{e^{-t \tau_{0}}}{T_{\alpha} t+\beta}
$$

In the formula: $T_{\alpha}$ is the time constant for diesel engine rotating speed that rise; $\tau_{0}$ is the delay time for diesel engine torque pulse; $\beta$ is the self-adjustment coefficient for diesel engine; $t$ is the time variable; $A$ is the proportional coefficient of the change of the gear lever position to the output torque.

\subsection{Electromagnetic actuators}

The electromagnetic actuator is a kind of electromagnet which is made by the solenoidal induction principle, and the actuator convert the output voltage of governor into the output shaft displacement which is proportional to input signal. The actuator is composed of a lever mechanism and a screw transmission mechanism. We can build its model according to the step response experiment, so the mathematical function can be simplified as a second order segment [9], namely:

$$
G_{2}(t)=\frac{1}{T_{r}^{2} t+T_{p} t+\delta}
$$

In the formula: $\delta$ is local inhomogeneous degree of the electromagnetic force and the spring wire; $T_{p}$ is the viscous friction time constant for the actuator motor system; $T_{r}$ is the inertial time constant for actuator motion quality system.

\subsection{Speed feedback segment}

The speed feedback segment of digital electronic governor is mainly composed of revolution speed transducer and signal conversion circuit. Its working process is that the signal conversion circuit transforms frequency signal which is obtained by revolution speed transducer into a square wave pulse signal. The speed can be measured according to the time interval between two pulses. The segment's input is the rotation speed of engine, and its output is a voltage signal which is proportional to rotating speed. The frequency from the magnetic sensor is converted into the pulse signal proportional to rotation speed, the mathematical function can be regarded as a proportional segment [10], that is to say:

$$
G_{3}(t)=K_{0}
$$

In the formula: $K_{0}$ is amplification coefficient for speed measuring channels.

\subsection{The mathematical control model of engine speed control system}

Actuator adopts stepper motor, and fuel quantity control mechanism consists of a rotating electromagnet, and the rotation of the armature is proportional to the displacement of the sliding sleeve, so its incremental equation of motion is as follows:

$$
m \frac{\partial^{2} y}{\partial t^{2}}+D \frac{d y}{d t}+K_{s} y=\Delta F_{m}
$$


In the formula: $y$ indicates the changes of the armature displacement; $m$ is the quality of the armature push rod assembly; $D$ is the damping coefficient; $K_{s}$ is time dependable and reset spring stiffness; $\Delta F_{m}$ is the electromagnetic force increment, in the work area which can be expressed as:

$$
\Delta F_{m}=K_{1} \Delta i-K_{x} \Delta x
$$

In the formula: $K_{I}$ the current force gain of proportion electromagnet; $K_{x}$ is the sum of displacement force gain of proportion electromagnet and the spring stiffness of proportion electromagnet. $K_{x}$ is also time dependable.

The above two formulas are incorporated, then it is transformed by laplace theorem, resulting in:

$$
m s^{2} \Delta x+D_{s} \Delta x+K_{x} \Delta x=K_{1} \Delta i-K_{x} \Delta x
$$

The transfer function of the fuel quantity control mechanism is obtained, as follows:

$$
\begin{aligned}
& G(s)=\frac{\Delta x}{\Delta i}=\frac{K_{1}}{\frac{s^{2}}{\omega^{2}}+\frac{2 \xi}{\omega} s+1}=\frac{K_{1} \omega^{2}}{s^{2}+2 \xi \omega s+\omega^{2}} \\
& \omega=\sqrt{\left(K_{s}+K_{x}\right) / m} \\
& \xi=\frac{D / 2}{\sqrt{\left(K_{s}+K_{x}\right) / m}}
\end{aligned}
$$

The timing control mechanism is through the control of the high side switch valve of high pressure cylinder to change the amount of the high pressure fuel within the cavity, and then to change the timing piston position, so it can realize the fuel injection timing adjustment [11]. Based on experience, the parameters are taken $\omega=32.6$, $\xi=0.704$. So the actuator's transfer function is defined as follows:

$$
G_{1}(s)=\frac{1062}{s^{2}+46 s+1062}
$$

\section{Adaptive fuzzy PID controller of diesel engine speed control system}

\subsection{The mathematical control model of engine speed control system}

The difference between adaptive fuzzy PID controller and traditional PID controller is that the adaptive fuzzy PID controller can easily adapt to the real-time requirements of dynamic system. The implementation idea is to find out the fuzzy relationship among the three parameters of traditional PID, the deviation and deviation change rate, which can be detected in the real time running state. The three traditional PID parameters are modified online according to the fuzzy inference mechanism. Then the computer use fuzzy reasoning to automatically adjust PID parameters according to the actual situation of control system, which can ensure the control system have a good dynamic and steady-state performance. Although the traditional PID controller has features of simple structure, reliability and stability and most of the speed control system has applied it, the traditional PID control may fail to handle large influence of model parameters and load. So, the traditional PID controller can't satisfy the requirements of high precision and performance in the occasion of system with large disturb. Traditional PID regulator doesn't have the function of online tuning parameters. If the PID parameter online self-tuning can be realized, it can further improve the performance of PID controllers. Therefore, the PID controller and fuzzy controller are combined, so that it can meet the requirements of PID parameters self-tuning under the different situation and make the control effect more ideal. The adaptive fuzzy PID controller can be directly used in the control of the speed regulation system [12-16], and the characteristics of fuzzy control applied to the nonlinear time varying, the control of lag system and strong robustness are fully reflected. Because the establishment of the controlled object does not need the accurate mathematical control model, so it is more convenient to devise. The structure diagram is shown in Fig. 2.

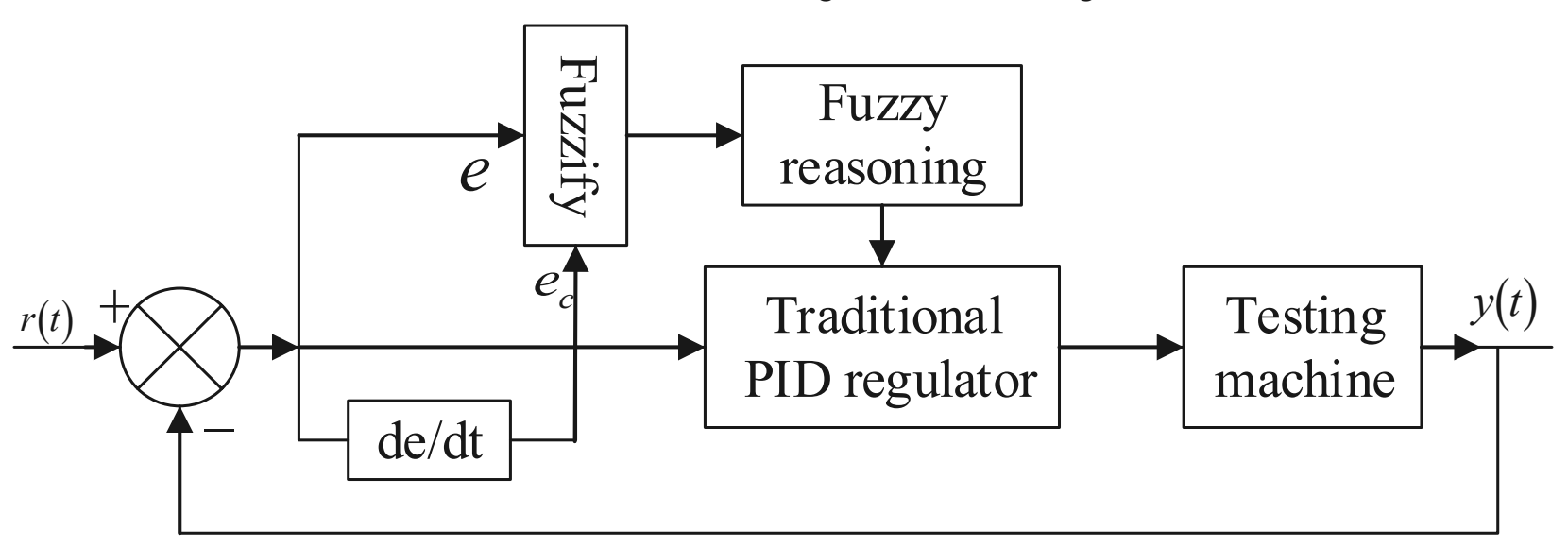

Fig. 2 The structure diagram of adaptive fuzzy PID Controller

In Fig. 2, $r$ is setting value; $e$ is the error fuzzy quantity; $e_{c}$ is error rate; $K_{p}$ is proportional coefficient; $K_{i}$ is integral coefficient; $K_{d}$ is differential coefficient; de/dt is the error change speed; $y(t)$ is the amount to be adjusted. $e$ and $e_{c}$ are the input variables. $K_{p}, K_{i}$ and $K_{d}$ are the output variables. In the course of engine running, the fuzzy adaptive PID controller can execute fuzzy reasoning according to the fuzzy rules by constantly detecting $e$ and 
$e_{c}$, and the $K_{p}, K_{i}$ and $K_{d}$ are modified online, to meet the different requirement to the controller parameters of constantly changing $e$ and $e_{c}$. Such control method can help the controlled object have good dynamic and static performance. Besides, the amount of calculation is small, which means that it can be achieved easily on the computer.

In the fuzzy PID control system with a large extent, the control performance depends on the selection of $K_{p}$ value, increasing $K_{p}$ can reduce the steady state error and improve the adjustment precision and the response speed [17]. But if the $K_{p}$ is too large, it will cause the adjustment procedure to produce larger overshoot, and even lead to system instability. Reducing $K_{p}$ can reduce the overshoot and improve the stability. If the $K_{p}$ is too small, it will reduce the regulation accuracy and slow down response speed. In the initial adjustment, the ratio $K_{p}$ of PID regulator was appropriately amplified to the larger level to improve the response speed. In the regulation of the medium-term, the $K_{p}$ need be placed largely, and take into account both the stability and accuracy of regulation, so as to improve the control precision.

\subsection{The determination of control rules}

We can see that the error system is multi-dimensional fuzzy controller with two input and three output which takes error $e$ and error rate $e_{c}$ as input language variable and takes accommodation coefficient $K_{p}, K_{i}$ and $K_{d}$ of the regulator as output language variable from fuzzy control system structure [18]. Error and error change rate is sufficient to describe the relationship between the input and output of the whole system, and the tuning of PID parameters must consider the interaction and interconnection relationship of control parameters $K_{p}, K_{i}$ and $K_{d}$. In accordance with the relevant experience, we divide the PID controller into 4 scenarios for discussion:

(1)When $|\mathrm{e}(\mathrm{k})|>\mathrm{M}_{1}\left(\mathrm{M}_{1}\right.$ is the maximum of the region with $0<$ error $<1$ ), the absolute value of error will be great, no matter how the error varies at this time, and the controller are supposed to adjust error value quickly and to give the proper output according to the output of the biggest adjustment, which makes the error reduce timely.

(2) When $\mathrm{e}(\mathrm{k}) \Delta \mathrm{e}(\mathrm{k})>0$, the analysis shows that the error change toward the direction of its absolute value increasing, if $\mathrm{M}_{2}>\mathrm{M}_{1}$, and $|\mathrm{e}(\mathrm{k})|>\mathrm{M}_{2}\left(\mathrm{M}_{2}\right.$ is the maximum of the region with error $<0$ ), at this point, the error value is large, therefore, the control function of the controller should be enhanced, so that the error value is changed to the direction of the decrease.

(3) When $\mathrm{e}(\mathrm{k}) \Delta \mathrm{e}(\mathrm{k})<0$, at this point, either the error increment or the absolute value of the error are the trend of the reduction, then the constant output of the controller is considered.

(4)When $|\mathrm{e}(\mathrm{k})|<\varepsilon$ ( $\varepsilon$ is the given tiny value), it can introduce integral link at this time and the purpose is to reduce the steady-state error of the system.

Thus, when the deviation value of the system is different, the three parameters of PID should also take different values, which requires the PID has the function of their own setting. Fuzzy PID controller takes it as a goal, and the idea of fuzzy mechanism and fuzzy reasoning is adopted on the basis of traditional PID regulation, which helps to execute online self-tuning fuzzy control for traditional PID parameters $\mathbf{K}_{\mathbf{p}}, \mathbf{K}_{\mathbf{i}}$ and $\mathbf{K}_{\mathbf{d}}$ according to the different $\mathbf{e}$ and $\mathbf{e}_{c}$. Its structure is mainly composed of two parts: the traditional PID control and fuzzy reasoning parameter correction part.

\subsection{The fuzzy processing of the input error and the error rate}

The variable from the fuzzy controller port in and out are accurate, and the fuzzy reasoning is conducted in view of the fuzzy quantity. Therefore, the first thing to do for controller is fuzzy processing of the input variables. In this paper, the fuzzy adaptive PID controller is designed, and the values of input and output are set as seven languages values: negative big, negative middle, negative small, zero, positive small, positive middle, positive big, namely NB, NM, NS, ZO, PS, PM, PB, and the membership function is a trigonometric function with a strong sensitivity, and all parameters are subject to normal distribution, as shown in Fig. 3.

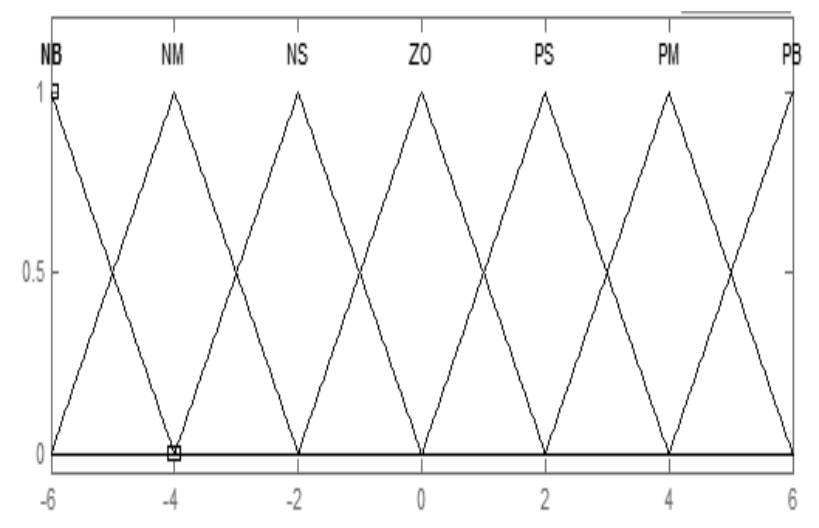

Fig. 3 The curve of the membership function

Error $e$, error change rate $e_{c}$ and the discourse domain of output control quantity take for $\{-6,-4,-2,0,2,4,6\}$, fuzzy control rules table are shown in Tab. 1, Tab. 2 and Tab. 3 in view of the three parameters, and respectively setting. where: NB represents negative big, its value is -6 ; NM represents negative medium, its value is -4 ; NS represents negative small, its value is -2 ; ZR is zero; PS represents positive small, its value is 2 ; PM represents positive medium, its value is 4; $\mathrm{PB}$ represents positive big, its value is 6 .

Tab. 1 The control rule table of $K_{p}$

\begin{tabular}{|c|c|c|c|c|c|c|c|}
\hline $\mathrm{e}^{\mathbf{e}_{\mathrm{c}}}$ & NB & NM & NS & ZO & PS & $\mathbf{P M}$ & PB \\
\hline NB & PB & PB & PB & PB & PB & PB & PB \\
\hline NM & PB & PS & PS & PS & PS & PS & PS \\
\hline NS & ZO & ZO & ZO & ZO & ZO & NS & NS \\
\hline $\mathrm{ZO}$ & NS & NS & NS & NS & NS & NB & NB \\
\hline PS & ZO & ZO & $\mathbf{Z O}$ & ZO & $\mathbf{Z O}$ & NS & NS \\
\hline $\mathbf{P M}$ & PB & PS & PS & PS & PS & PS & PS \\
\hline PB & PB & PB & NS & NM & NM & NB & NB \\
\hline
\end{tabular}


Tab. 2 The control rule table of $K_{i}$

\begin{tabular}{|c|l|l|l|l|l|l|l|}
\hline e & NB & NM & NS & ZO & PS & PM & PB \\
\hline NB & PS & ZO & ZO & ZO & ZO & PS & PS \\
\hline NM & NB & NB & NM & NS & NM & PS & NB \\
\hline NS & NB & NB & NM & NS & NM & NS & NB \\
\hline ZO & NS & NS & NS & NS & NS & NM & NM \\
\hline PS & NB & NB & NM & NS & NM & NB & NB \\
\hline PM & NB & NB & NM & NS & NM & PS & PS \\
\hline PB & PS & PS & ZO & ZO & ZO & PS & PS \\
\hline
\end{tabular}

Tab. 3 The control rule table of $K_{d}$

\begin{tabular}{|l|l|l|l|l|l|l|l|}
\hline e & NB & NM & NS & ZO & PS & PM & PB \\
\hline NB & PB & PB & PM & PM & PS & ZO & ZO \\
\hline NM & PB & PB & PM & PM & PS & ZO & ZO \\
\hline NS & PM & PM & ZO & NS & NM & NB & NB \\
\hline ZO & PB & PB & PM & ZO & NM & NB & NB \\
\hline PS & PM & PM & ZO & NS & NM & NB & NB \\
\hline PM & ZO & ZO & NS & NM & NM & NB & NB \\
\hline PB & ZO & NB & NB & NB & NB & NB & NB \\
\hline
\end{tabular}

Put the modified parameters into formula (6) to calculate the parameters of PID controller through a series of look-up table, models reasoning.

$$
\begin{aligned}
& K_{p}=K_{p}^{\prime}+\left\{e_{i}, e_{c_{i}}\right\} \times q_{p} \\
& K_{i}=K_{i}^{\prime}+\left\{e_{i}, e_{c_{i}}\right\} \times q_{i} \\
& K_{d}=K_{d}^{\prime}+\left\{e_{i}, e_{c_{i}}\right\} \times q_{d}
\end{aligned}
$$

Where: $K_{p}^{\prime}, K_{i}^{\prime}$ and $\mathbf{K}_{\mathbf{d}}{ }^{\prime}$ is the last time reserved values $K_{p}, K_{i}$ and $K_{d}$ for the fuzzy controller. The parameters need to plus the corresponding deviation and variation value of the controller and be applied to the control object. When the system runs Online, the controller carries on the logic reasoning, look-up table and operation according to the fuzzy rules, so the parameters of PID can correct automatically online.

\section{Adaptive Fuzzy PID Controller}

The typical two-order transfer function is commonly used in the industrial process. In this paper, a fuzzy controller is established according to the control rules and the relationship between the input and output of the fuzzy controller, which is respectively shown in Fig. 4, Fig. 5 and Fig. 6.

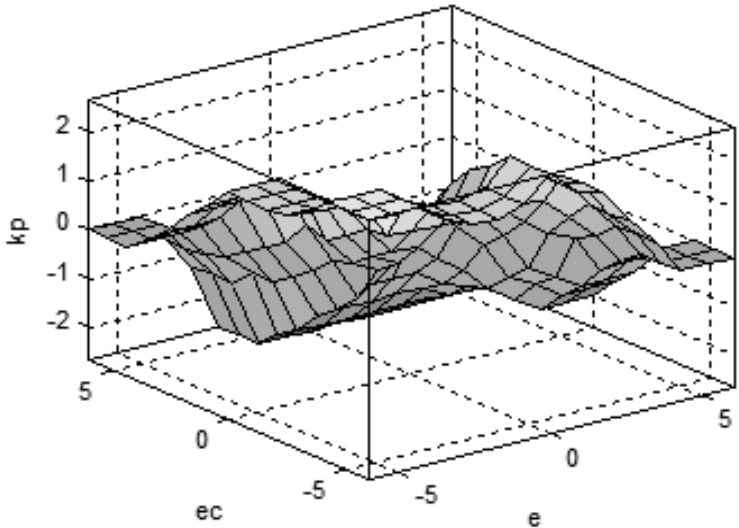

Fig. 4 The relationship between error $\boldsymbol{e}$, error rate $\boldsymbol{e}_{c}$ and proportional coefficient $\boldsymbol{K}_{\boldsymbol{p}}$

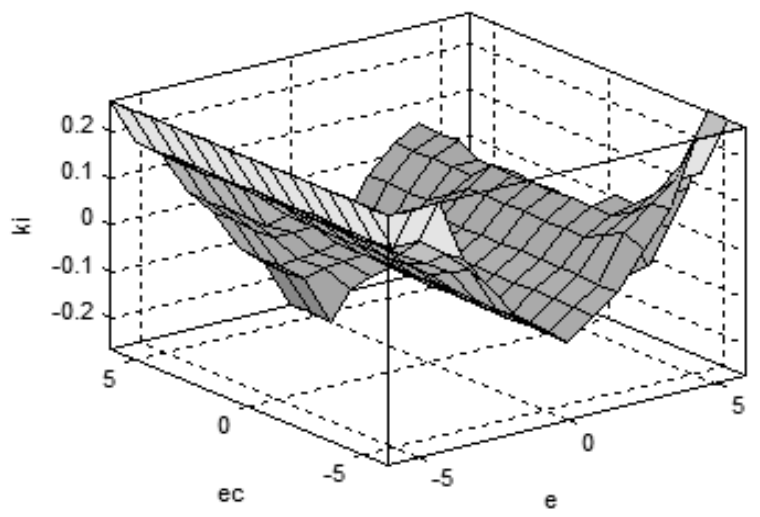

Fig. 5 The relationship between error $\boldsymbol{e}$, error rate $\boldsymbol{e}_{c}$ and integral coefficient $\boldsymbol{K}_{\boldsymbol{i}}$

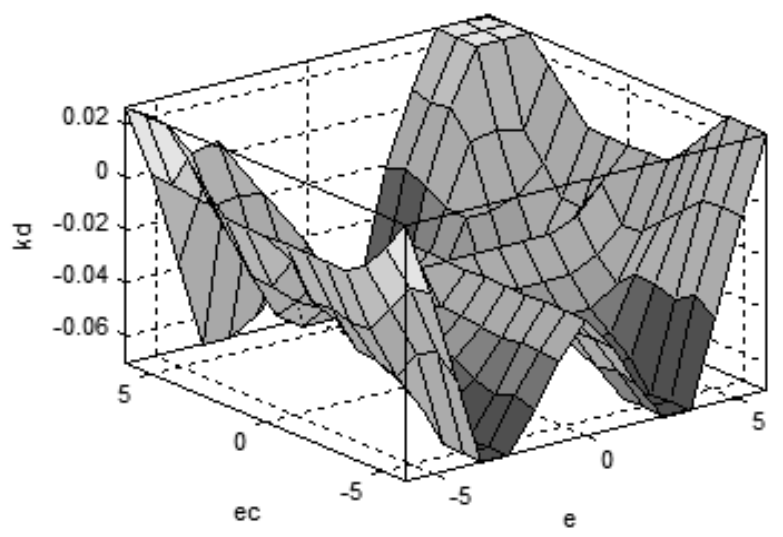

Fig. 6 The relationship between error $\boldsymbol{e}$, error rate $\boldsymbol{e}_{\boldsymbol{c}}$ and differential coefficient $\boldsymbol{K}_{\boldsymbol{d}}$

The above three Figures show the dynamic process of the fuzzy controller tuning the related parameters of the PID controller. From the Figures, the proportion coefficient $K_{p}$ is changed smoothly by the fuzzy controller, but the integral coefficient $K_{i}$ and the differential coefficient $K_{d}$ have larger fluctuations. However, large amplitude adjustment of the integral coefficient $K_{i}$ and differential coefficient $K_{d}$ of PID controller and small amplitude adjustment of proportional coefficient $K_{p}$ of PID controller by fuzzy controller can make the output of the PID controller change rarely, so as to improve the control precision of the PID controller. 


\section{Simulation and Results}

Fig. 7 presents the simulation structure diagram which includes the fuzzy PID controller and the traditional PID controller. The simulation output waveform is shown in Fig. 8.

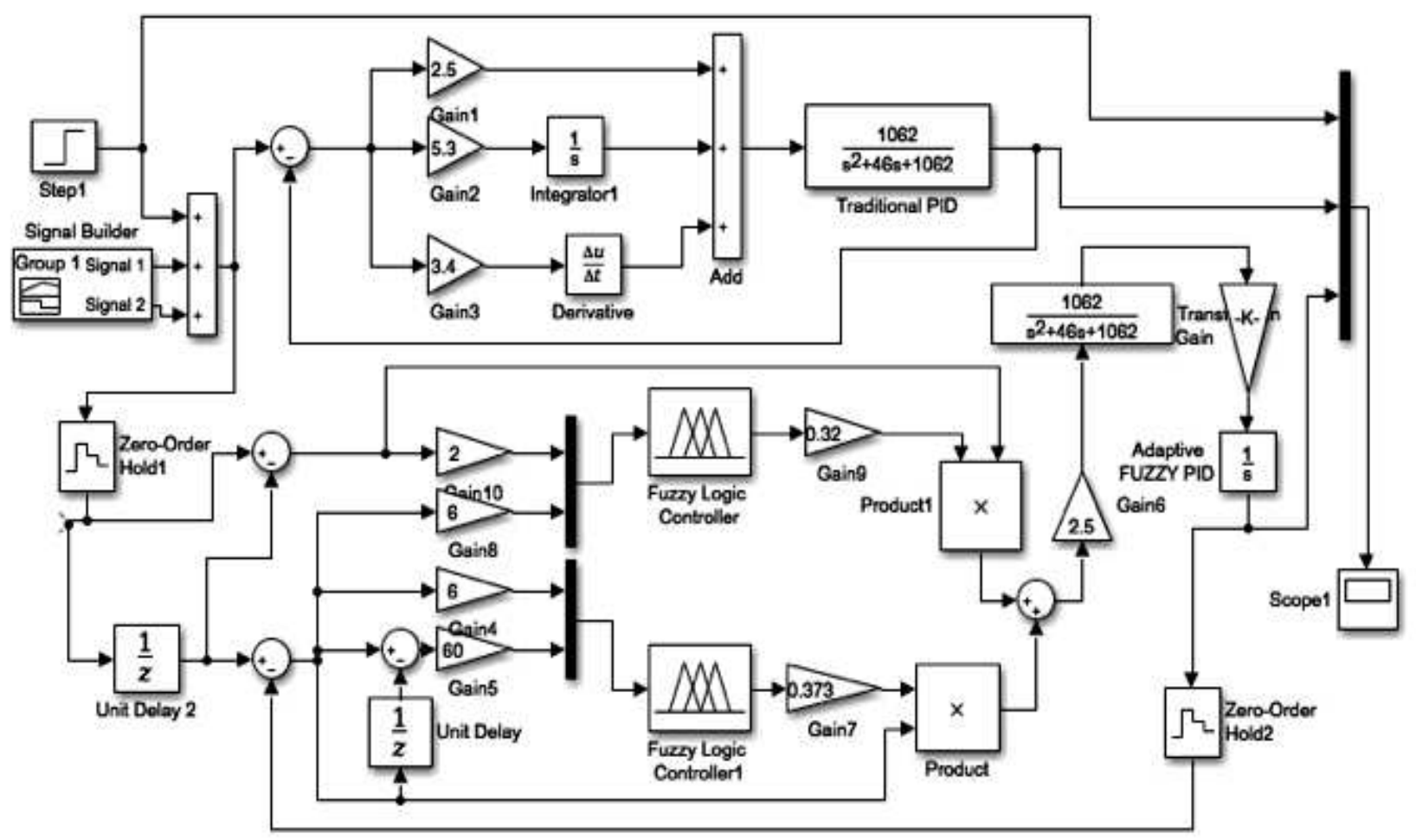

Fig.7 Simulink simulation structure diagram

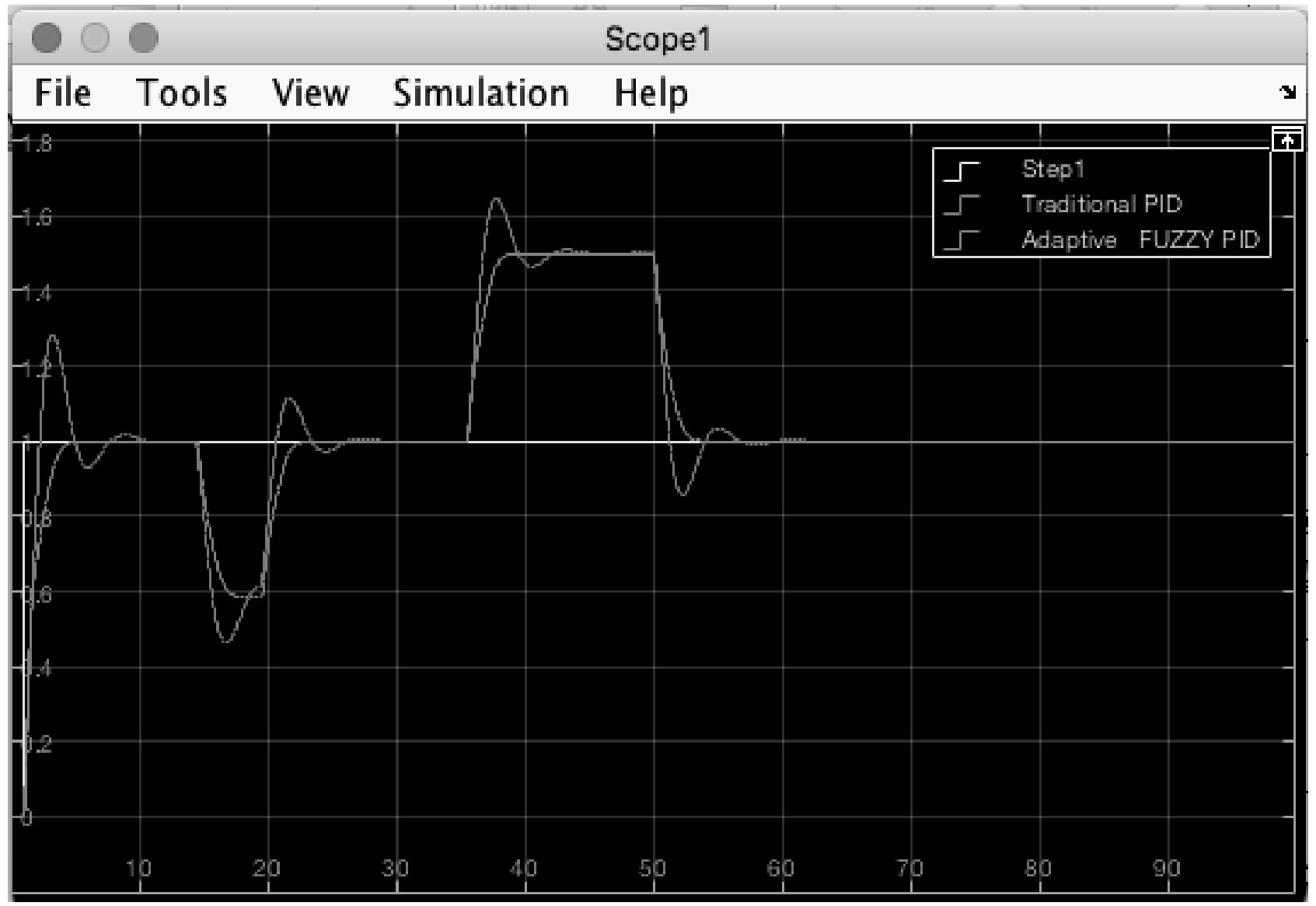

Fig. 8 The simulation waveform 
In this study, a mathematical model of the diesel engine speed system is developed and disturb is added to the system. Apart from that, the diesel engine speed system is controlled by the traditional PID controller and the adaptive fuzzy PID controller. The simulation results show that the traditional PID controller has higher overshoot and settling time than the adaptive fuzzy PID controller. Hence, adaptive fuzzy PID controller design was proposed and implemented with the principles of artificial intelligence. The adaptive fuzzy PID controller shows a better control effect as compared with the traditional PID controller.

Tab. 4 Comparison of traditional PID controller and adaptive fuzzy PID controller

\begin{tabular}{|c|l|c|c|c|}
\hline No. & controller & $\begin{array}{l}\text { Max } \\
\text { overshoot }\end{array}$ & $\begin{array}{l}\text { Settling } \\
\text { Time }\end{array}$ & $\begin{array}{l}\text { SS Er- } \\
\text { ror }\end{array}$ \\
\hline 1 & $\begin{array}{l}\text { Traditional } \\
\text { PID con- } \\
\text { troller }\end{array}$ & $48.5 \%$ & 10 & $1.4 \%$ \\
2 & $\begin{array}{l}\text { Adaptive } \\
\text { fuzzy con- } \\
\text { troller }\end{array}$ & 0 & 4 & $0.2 \%$ \\
\hline
\end{tabular}

The Fig. 8 and Tab. 4 show that the response time of adaptive fuzzy PID controller is far less than the traditional PID controller and the output of the adaptive fuzzy PID can quickly reach the steady state, which indicates that the adaptive ability of the system has been greatly improved. It may be safely said that the adaptive fuzzy PID controller has a better adaptability and steady state performance.

\section{Conclusions}

This paper presented an adaptive fuzzy PID control method for the diesel engine speed control system that is accompanied by the uncertainty and time variability. From the simulation comparing the traditional PID controller with the adaptive fuzzy PID controller, we observed that the adaptive fuzzy PID controller can make a significant improvement in shortening the adjustment time and reducing the overshoot, which help to enhance the stability and anti-disturb capability of the system.

\section{Acknowledgement}

This work was supported by National Natural Science Foundation of China grants program (No.61263023 and No.61863016).

\section{References}

[1] JIN, T., QU, L., LIU, S., GAO, J., WANG, J., \& WANG, F., ET AL. (2014). Chemical characteristics of particulate matter emitted from a heavy duty diesel engine and correlation among inorganic and pah components. In: Fuel, Vol. 116, No. 1, pp. 655-661.
[2] LIAO Y. Y., LIAO B. Y. (2019). Dynamics Modeling and Modal Analysis of Machine Tool Considering Joints Parameters. In: Manufacturing Technology, Vol. 19, No. 2, pp. 267-272.

[3] JIAN, F., MARÉ, JEAN-CHARLES, \& YONGLING, F. (2016). Modelling and simulation of flight control electromechanical actuators with special focus on model architecting, multidisciplinary effects and power flows. In: Chinese Journal of Aeronautics, Vol. 30, No.1, pp. 47-65. S1000936116301996.

[4] ZHENG, H., ZENG, Q., CHEN, W., ZHU, H., \& CHEN, C. (2017). Improved PID control algorithm for quadrotor based on MCS. In: Guidance, Navigation \& Control Conference. IEEE.

[5] PETRU M., MLYNEK J., MARTINEC T. (2018). Numerical Modelling for Optimization of Fibres Winding Process of Manufacturing Technology for the Non-Circular Aerospaces Frames. In: $M a$ nufacturing Technology, Vol. 18, pp. 90-98.

[6] SEGLA S., KAMPO J. (2018). The Role of Modelling of Road Unevennesses in Vehicle Dynamics. In: Manufacturing Technology, Vol. 18, pp. 124-129.

[7] SAPIETA M., SULKA P., SVOBODA M. (2018). Using a Numerical Model to Verification of Thermoelastic Analysis of Flat Specimen. In: Manufacturing Technology, Vol. 18, pp. 482-486.

[8] ZHU, D. H., HONG, Y. Z., \& ZHU, H. Q. (2009). Mathematical model and control of magnetic bearings based on $\alpha$-th order inverse system theory. In: Electric Machines \& Control, Vol. 529, No. 04, pp. 539-543.

[9] FENG, X., JIAN-HUA, W., \& CHENG-JIAN, G. (2011). Research of fuzzy-pid controller for diesel engine idle speed control. In: Tractor \& Farm Transporter, Vol. 38, No. 3, pp. 43-45.

[10] SUN B.-L., FAN J.-Z., SHI. (2010). Research on Fuzzy-PID Combined Speed Governing and Rapid Control Prototyping of Marine Diesel Engine. In: Chinese Internal Combustion Engine Engineering, Vol. 31, No. 4, pp. 54-58.

[11] VARGAS-MARTÍNEZ, ADRIANA, MINCHALA-AVILA, L. I., ZHANG, Y., GARZA-CASTAÑÓN, LUIS EDUARDO, \& ACOSTA-SANTANA, P. (2015). Fault-tolerant controller design for a master generation unit in an isolated hybrid wind-diesel power system. In: International Journal of Robust and Nonlinear Control, Vol. 25, No. 5, pp. 761-772.

[12] MAHTO, T., \& MUKHERJEE, V. (2017). Fractional order fuzzy pid controller for wind energybased hybrid power system using quasi-oppositional harmony search algorithm. In: IET Generation, Transmission \& Distribution, Vol. 11, No. 13, pp. 3299-3309. 
[13] MA, J., \& JI, R. (2016). Fuzzy PID for Quadrotor Space Fixed-Point Position Control. In: Sixth International Conference on Instrumentation \& Measurement. IEEE.

[14] YUSOF, A. M. (2013). Comparative study of conventional pid and fuzzy-pid for dc motor speed control. In: UTHM Institutional Repository.

[15] PAPADOPOULOS, K. G., TSELEPIS, N. D., \& MARGARIS, N. I. (2013). Type-iii closed loop control systems-digital pid controller design. In: Journal of Process Control, Vol. 23, No. 10, pp. 1401-1414.

[16] CHEN, X. H., RAHMAN, M. L., \& ZHANG, Y. (2016). Adaptive Fuzzy PID speed control of DC belt conveyor system. In: 2016 17th IEEE/ACIS International Conference on Software Engineering, Artificial Intelligence, Networking and Parallel/Distributed Computing (SNPD). IEEE.

[17] YAQI, R., ZHAOSHENG, T., QIANG, H., YAKUN, L., \& HAIJUN, L. (2015). Research on the fuzzy-pid adjustment method of electronic analytical balance. Chinese Journal of Scientific Instrument, Vol. 36, No. 6, pp. 1424-1432.

[18] ROJAS, I., POMARES, H., GONZALEZ, J., HERRERA, L. J., GUILLEN, A., \& ROJAS, F., ET AL. (2006). Adaptive fuzzy controller: application to the control of the temperature of a dynamic room in real time. In: Fuzzy Sets and Systems, Vol. 157, No. 16, pp. 2241-2258. 